\title{
Computed Tomography And Ultrasound Guided Fine Needle Aspiration Cytology In The Diagnosis Of Intraabdominal And Pelvic Lesions: A Single Institutional Experience
}

\author{
Cheryl Sarah Philipose ${ }^{1}$, Ashima N.Amin ${ }^{2 *}$ and Jayaprakash C.S ${ }^{2}$ \\ ${ }^{1}$ KasturbaMedicalCollege, Mangaluru, India \\ ${ }^{2}$ Fathermullermedicalcollege,Mangaluru, India
}

\begin{abstract}
Background: Fine needle aspiration cytology(FNAC) as an initial screening modality is an important interventional method.Technical advances in the method of radiology have it made it possible for many inaccessible lesions within the abdomen and pelvis to be safely sampled.Although FNA yields limited material, a positive diagnosis can contribute to the treatment,thus limiting the need for a core biopsy or 2 step surgical procedure. The procedure is relatively inexpensive and can also be done on an outpatient basis with minimal morbity to the patient.

Methods: The present study is a retrospective study carried out from January 2012 to October 2014. All the patients in whom intra abdominal and pelvic lesions were detected clinically and by imaging modalities such as CT and USG, were included. The alcohol fixed (PAP) and air dried (MGG) smears of the selected cases were retrieved from archives and cytomorphological features were studied.

Result: A total of 755 aspirations were carried out under image guidance, of which 208 aspirates (27.54\%) included only intraabdominal and intrapelvic lesions. Majority of the patients in the study were males (51\%). Total number of inflammatory lesions were 16 cases, benign lesions were 10 cases and malignant lesions were 164 cases. The most commonly encountered malignancy was metastasis to the liver .

Conclusion: CT and USG guided FNAC is able to overcome various obstacles such as inaccessibility of deep seated intraabdominal lesions and is a valuable tool for yielding cellular smears.
\end{abstract}

Keywords: Computed Tomography, FNAC, Ultrasound, Intraabdominal, Intrapelvic.

\section{Introduction}

The clinicopathological evaluation of intraabdominal and pelvic lesions is often challenging and remains and enigma, both to the clinician as well as the pathologist. ${ }^{[1]}$ Although many palpable and non palpable, deep seated lesions can be demonstrated by the newer imaging modalities, they often have a limited role in differentiating benign and malignant lesions. A definitive tissue diagnosis remains mandatory for the evaluation and management of the patient. ${ }^{[2]}$ Althought histopathology is the gold standard for pathological diagnosis, Fine needle aspiration cytology(FNAC) is being used increasingly as the method is found to be rapid, sensitive, inexpensive and reliable with less morbidity to the patient. ${ }^{[3]}$ It can be done on an outpatient basis and is also suited for debilitated patients

\section{Materials and Methods:}

The present study is a retrospective study carried out in the Department of Pathology from January 2012 to October 2014 (34 months). All the patients in whom intraabdominal and pelvic lesions were detected clinically and by imaging modalitites such as CT and USG, were included in our study. The relevant data such as age, sex, clinical details, laboratory investigations were recorded from the case records of the patients. The aspirations in each case was performed by the radiologist in conjunction with the pathologist, under image guidance, after obtaining informed consent from the patient. The choice of imaging modality was determined by the radiologist. The alcohol fixed (PAP) and air dried (MGG) smears of the selected cases were retrieved from archives. The cytomorphological features were studied. Smears with inadequate cellularity and those obscured by blood were also excluded from the present study.

\section{Result}

A total of 755 aspirations were carried out under image guidance, of which 208 aspirates (27.54\%) included only intraabdominal and intrapelvic lesions. Majority of the patients in the study were males $(51 \%)$. The most common age group was 51 to 60 years (picture 1). The various sites of aspiration included the liver, ovary, kidney, pancreas, spleen, stomach, adrenal gland, intraabdominal lymph nodes, sacral masses, omental deposits, retroperitoneal 
masses and pelvic lesions (table 1).Out of 208 aspirates thirty eight aspirates $(18.3 \%)$ were found to be unsatisfactory for evaluation due to either low cellularity or haemorrhage and hence were excluded from the study.

Total number of inflammatory lesions were 16 cases (9.4\%), benign lesions were 10 cases (5.9\%) and malignant lesions were 154 cases $(90.6 \%)$. The most common site of aspiration was the liver (114 cases, 67\%), followed by ovary (13 cases, $7 \%$ ) and intraabdominal lymph nodes (5 cases, $2.9 \%$ ). The most commonly encountered malignancy was metastasis to the liver (68 cases, $40 \%$ ) followed by Hepatocellular carcinoma (35 cases, 29.9\%).Malignant surface epithelial tumors of the ovary accounted for the third most commonly encountered malignancy in the abdomen, comprising 12 cases (92.3\%).Malignant lesions were also encountered in intraabdominal lymph nodes, pancreas, kidney, stomach and adrenal gland.(pictures 2,3 4,5 and 6)

Most of the benign lesions were seen in the liver (8 cases) of which the majority were regenerative nodules, closely followed by adenomas. The other benign lesions encountered in the study were 2 benign cystic lesions, one in the pancreas and the other in pelvic region.

Of the inflammatory lesions, abscess was the most common lesion. Out of 6 abscesses, 3 cases were located in the liver. Other inflammatory lesions in the intraabdominal lymph nodes included reactive lymph node (4 cases) and granulomatous lymph node (1 case).

Histopathological confirmation was available for 26 cases of which 20 cases were found to be correlating with a diagnostic accuracy of $76.92 \%$ (tables 2 and 3 )

Tables: 1

\begin{tabular}{|c|c|c|c|c|c|c|}
\hline Site & $\begin{array}{l}\text { Inflammatory (no } \\
\text { of cases) }\end{array}$ & $\%$ & Benign (no of cases) & $\%$ & Malignant(no of cases) & $\%$ \\
\hline Liver & Abscess(3) & 1.75 & $\begin{array}{l}\text { Adenoma(3) } \\
\text { Regenerative nodule(4) } \\
\text { Vascular malformation(1) }\end{array}$ & $\begin{array}{l}1.75 \\
2.34 \\
0.58\end{array}$ & $\begin{array}{l}\text { HCC (35) } \\
\text { Metastatic } \\
\text { adenocarcinoma(34) } \\
\text { Metastatic SCC(5) } \\
\text { Metastatic poorly } \\
\text { differentiated } \\
\text { carcinoma(25) } \\
\text { Metastatic } \\
\text { neuroendocrine } \\
\text { carcinoma(1) } \\
\text { Metastatic myeloma(1) } \\
\text { Metastatic cystic } \\
\text { mucinous neoplasms(1) } \\
\text { Metastatic endometrial } \\
\text { stromal sarcoma(1) }\end{array}$ & $\begin{array}{c}20.48 \\
19.89 \\
2.92 \\
14.70 \\
0.58 \\
0.58 \\
0.58 \\
0.58\end{array}$ \\
\hline Ovary & Lymphocoele (1) & 0.58 & & & $\begin{array}{l}\text { Serous } \\
\text { cystadenocarcinoma(12) }\end{array}$ & 7.01 \\
\hline Kidney & Abscess (1) & 0.58 & & & $\begin{array}{l}\text { Non Hodgkins } \\
\text { Lymphoma(NHL)(2) } \\
\text { Renal Cell Carcinoma(1) }\end{array}$ & $\begin{array}{l}1.17 \\
0.58\end{array}$ \\
\hline Pancreas & $\begin{array}{l}\text { Pseudopancreatic } \\
\text { cyst (1) }\end{array}$ & 14.29 & $\begin{array}{l}\text { Macrocystic serous } \\
\text { adenoma(1) }\end{array}$ & 0.58 & $\begin{array}{l}\text { Adenocarcinoma(4) } \\
\text { Solid pseudopapillary } \\
\text { neoplasm(1) }\end{array}$ & $\begin{array}{l}2.34 \\
0.58\end{array}$ \\
\hline Stomach & & & & & $\begin{array}{l}\text { Adenocarcinoma(2) } \\
\text { Poorly differentiated } \\
\text { carcinoma(1) }\end{array}$ & $\begin{array}{l}1.17 \\
0.58\end{array}$ \\
\hline Adrenal & & & & & Metastatic carcinoma(1) & 0.58 \\
\hline $\begin{array}{l}\text { Intra } \\
\text { abdominal } \\
\text { lymph node }\end{array}$ & \begin{tabular}{|l} 
Reactive \\
lymphadenitis (4) \\
Granulomatous \\
lymphadenitis (1) \\
\end{tabular} & $\begin{array}{l}2.34 \\
0.58\end{array}$ & & & Metastatic carcinoma(1) & 0.58 \\
\hline Omentum & Tuberculosis(2) & 1.17 & & & Metastatic carcinoma(7) & 4.09 \\
\hline Iliopsoas region & Abscess(2) & 1.17 & & & $\begin{array}{l}\text { Small round cell tumor(1) } \\
\mathrm{NHL}(1)\end{array}$ & $\begin{array}{l}0.58 \\
0.58\end{array}$ \\
\hline
\end{tabular}




\begin{tabular}{|l|l|l|l|l|l|l|}
\hline Site & $\begin{array}{l}\text { Inflammatory (no } \\
\text { of cases) }\end{array}$ & $\%$ & Benign (no of cases) & $\%$ & Malignant(no of cases) & \% \\
\hline $\begin{array}{l}\text { Retro } \\
\text { Peritoneal mass }\end{array}$ & & & & & $\begin{array}{l}\text { Metastatic } \\
\text { adenocarcinoma(4) } \\
\text { NHL(1) }\end{array}$ & $\begin{array}{l}2.34 \\
0.58\end{array}$ \\
\hline Pelvic lesion & Hematoma(1) & 0.58 & Benign cystic lesion(1) & 0.58 & $\begin{array}{l}\text { Metastatic granulosa cell } \\
\text { tumor(1) } \\
\text { Gastrointestinal stromal } \\
\text { tumor(1) }\end{array}$ \\
\hline
\end{tabular}

Table 2: Cytohisto correlation (n-26).

\begin{tabular}{|c|c|c|c|}
\hline Cytology diagnosis & Number of cases & concordant & Discordant \\
\hline Benign & 8 & 6 & 2 \\
\hline Malignant & 18 & 14 & 4 \\
\hline Total & $\mathbf{2 6}$ & $\mathbf{2 0}$ & $\mathbf{6}$ \\
\hline
\end{tabular}

Table 3: discordant cases.

\begin{tabular}{|c|l|l|}
\hline No of cases & Cytological diagnosis & Histological diagnosis \\
\hline 2 & Hepatocellular carcinoma & Regenerative nodule \\
\hline 1 & Serous cystadenoma & Serous cystadenocarcinoma \\
\hline 3 & Poorly differentiated adenocarcinoma & Hepatocellular carcinoma \\
\hline
\end{tabular}

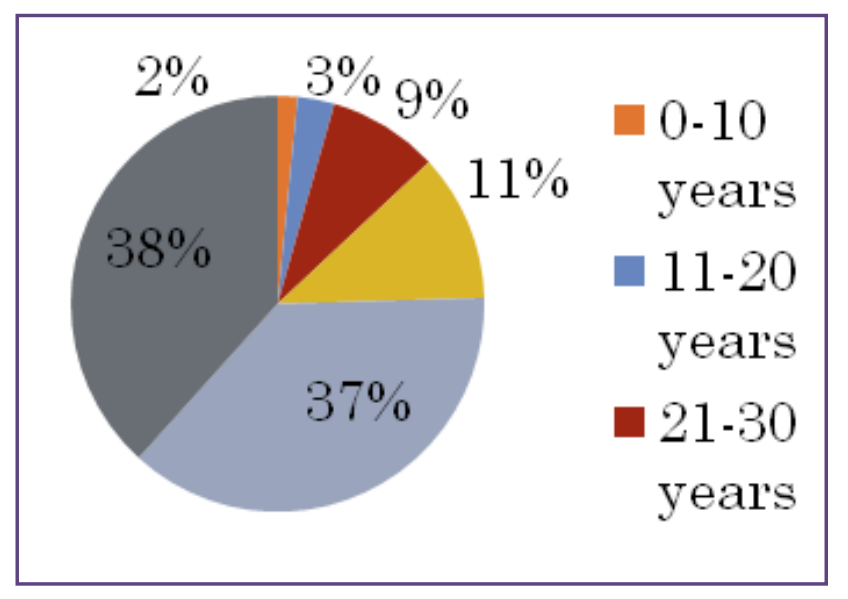

Pic. 1:Age distribution of intrabdominal and pelvic lesions.

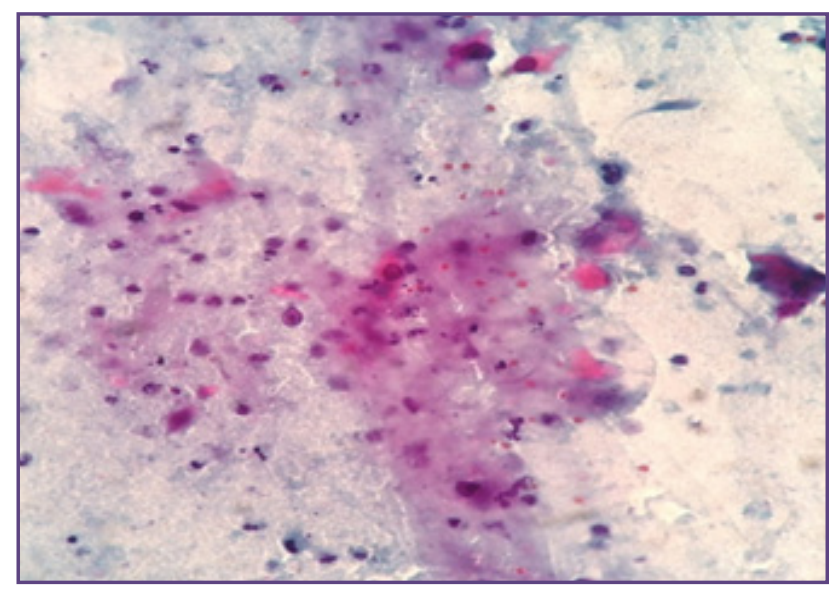

Fig. 3: FNA smears in metastatic squamous cell carcinoma showing keratinized malignant cells in singles.(papanicolaou x10)

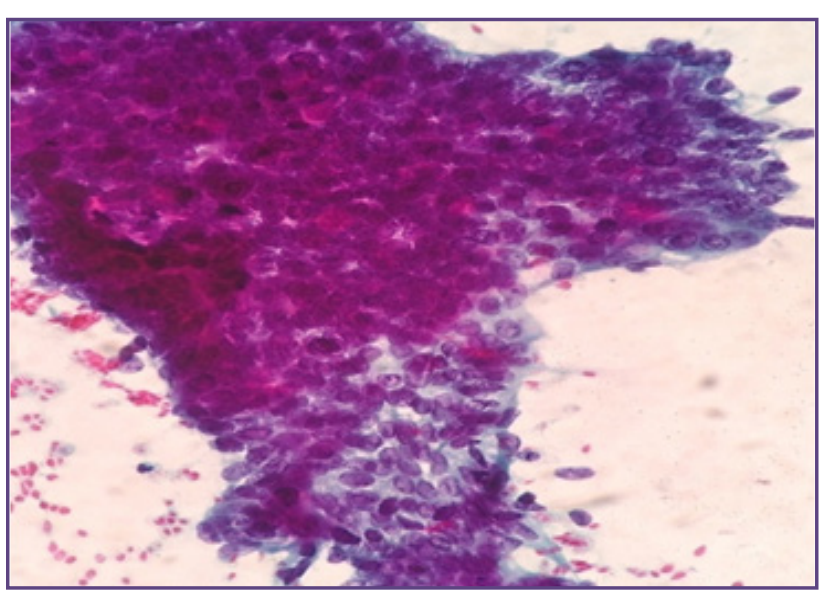

Fig. 2:FNAC smears in metastatic adenocarcinoma showing tumor cells arranged in sheets (papanicolaou x10).

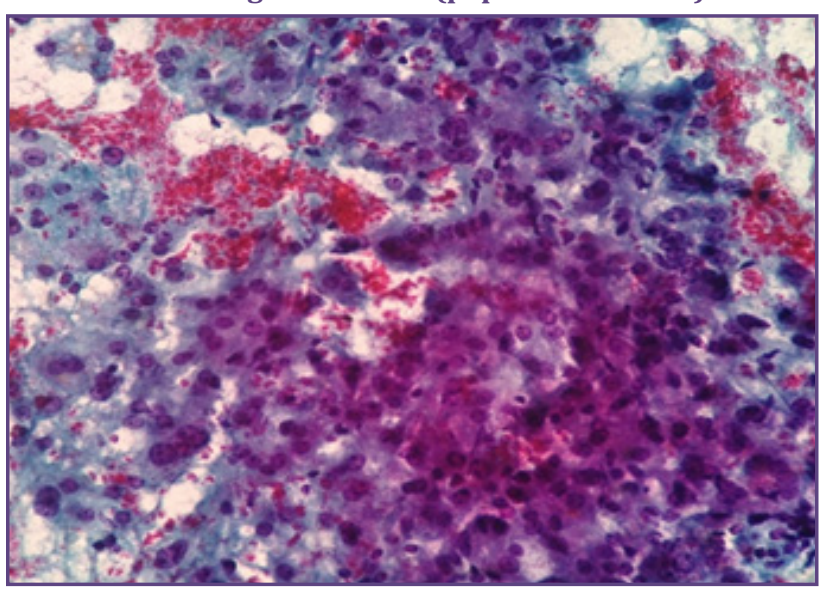

Fig. 4: FNAC smears in Regenerative nodule mimicking hepatocellular carcinoma (papanicolaou x40). 


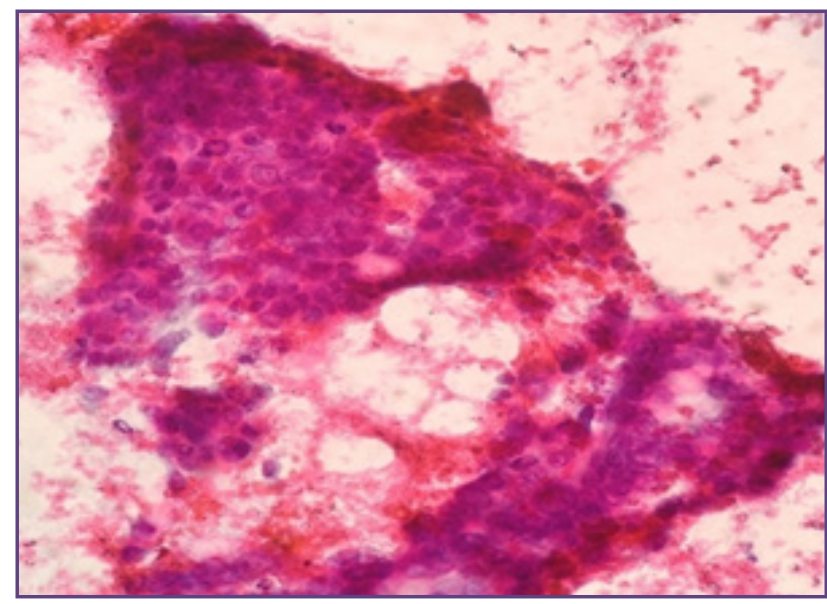

Fig. 5: FNAC smears in Solid Pseudopapillary Epithelial Neoplasm Pancreas(papanicolaou $\mathrm{x} 40$ ).

\section{Discussion}

CT and USG guided FNAC is a valuable tool in the diagnosis of various intraabdominal and intrapelvic lesions. Deep seated organs can safely be accessed with minimal discomfort to the patient. A good diagnostic yield increases the diagnostic accuracy and helps the clinician to formulate the treatment plan. In our study out of 208 guided aspirates, 170 aspirates yielded satisfactory material for diagnosis. The success rate of the procedure in our study was $81.7 \%$. This is in contrast to the success rate of $93 \%$ in a study done by Nautiyal $\mathrm{S}$ et al ${ }^{[1]}$. The experience of the radiologist plays an important role in obtaining good cellular aspirate.

In this study malignancy was the most common lesion .Similiar observation was made by Khan et al ${ }^{[2]}$ and Shamshad et al ${ }^{[3]}$. The most common site of aspiration was liver followed by ovary. These results are similar to studies done by Zawar et al ${ }^{[4]}$ and Reddy et al ${ }^{[50]}$.Among the liver lesions, the most common malignancy was metastasis to the liver, followed by Hepatocellular carcinoma.These findings are in accordance with the study done by RC

Adhikari ${ }^{[6]}$.However, Paranjuli et al ${ }^{[7]}$ in their study found hepatocellular carcinoma to be the most common malignancy. Among the metastasis to the liver, adenocarcinoma was found to be the most common, followed by poorly differentiated carcinoma and metastatic squamous cell carcinoma. This was comparable to studies done by Rani SG et al ${ }^{[8]}$. Other metastatic lesions included metastatic neuroendocrine tumour (4 cases), metastatic myeloma (1 case) and metastatic endometrial stromal sarcoma (1 case).

The ovary was the second most common site for malignancy. Aspiration from the ovarian in suspected ovarian malignancies is a matter of concern to several

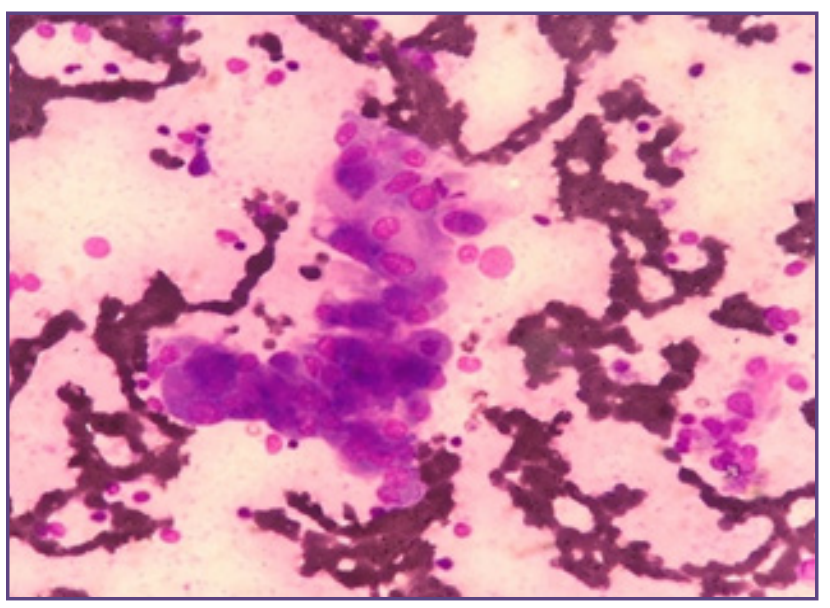

Fig. 6: FNAC smears in Renal cell carcinoma(May grunwald Giemsa stain $\mathrm{x40}$ ).

clinicians due to advertent seeding of the needle track. However, studies by Ray et al ${ }^{[9]}$ have refuted claims of such seeding of early stage of ovarian carcinoma while aspirating ovarian lesions. The authors believe that USG guided FNAC is safe and efficacious in the diagnosis of ovarian malignancies.

Among the renal lesions, there were 2 cases of NonHodgkins lymphoma. Studies by RC Adhikari et el ${ }^{[6]}$ found Renal cell carcinoma to be the most common malignancy in the kidney.

Of the Gastrointestinal lesions, the majority of the malignancies were noted in the pancreas, followed by the stomach. However, studies by Rani SG et al ${ }^{[8]}$ found the majority to be colonic malignancies.

Among the intraabdominal lymph nodes, 1 case was diagnosed as NHL, while 3 were found to be metastatic carcinoma. Parajuli et al ${ }^{[2]}$ found cases of NHL and 2 cases of metastasis to the lymph nodes. All the sacral and retroperitoneal masses were found to be malignant. Of these, one case was diagnosed as small round cell tumour and the other as NHL.

Among the benign lesions in our study, the most common site was the liver. Most of these lesions were regenerative nodules, closely followed by adenomas. This was in contrast to studies by Hemalatha et al ${ }^{[10]}$ who found benign surface epithelial tumors of the ovary to be the most common benign entity.

6 cases in our study were discordant with most cases observed in the liver.There was difficulty in distinguishing regenerative nodule and HCC in two cases. This difficulty has been faced by cytologists and has been explained by the fact that regenerating hepatocytes seen in cirrhosis and viral hepatitis may resemble well differentiated 
HCC. Poorly differentiated adenocarcinoma can resemble poorly differentiated heapatocellular carcinoma. Cytohistopathology discordance was observed in studies done by sidhalingareddy et al ${ }^{[11]}$ and shamshad et al ${ }^{[3]}$.

\section{Conclusion}

CT and USG guided FNAC is a valuable prileminary diagnositic modality which can overcome various obstacles such as inaccessibility of deep seated intraabdominal lesions. It is a valuable tool for yielding cellular smears and negates the necessity of expensive invasive investigations and lengthy hospital stay.

\section{Reference}

1. Nautiyal S., Mishra RK, Sharma SP., Routine and ultrasound guided FNAC of intra abdominal lumps - A comparative study. Journal of Cytology 2004;21(3):129-132

2. Khan AA., Jan GM., Wani NA. Fine Needle Aspiration of Intraabdominal masses for cytodiagnosis. J. Indian Med Assoc 1996; 94(5):167-69.

3. Ahmed SS, Akhtar K, Akhtar S et al. Ultrasound guided fine needle aspiration biopsy of abdominal masses. JK Science. 2006; 8(4):200-204

4. Zawar MP, Bolde S, Shete SS. Correlative study of FNAC and histology in intraabdominal lumps. SMJ. 2007;4.
5. Reddy S, Andola SK. FNAC of intraabdominal lesions. Journal of Clinical and Diagnostic research.2011; 5: 551-558.

6. Adhikari RC, Tuladhar A, Shrestha S, Sharma SK. Deep seated thoracic and abdominal lesions: Usefulness of ultrasound guided FNAC, a 3 year experience. Nepal Medical Coll J.2010;12:20-5

7. Parajuli S, Tuladhar A, Basnet RB. Ultrasound and computed tomography guided FNAC in diagnosing intraabdominal and intrathoracic lesions.Journal of Nepal 2011;2:17-21.

8. Rani SG, Faheem MKN, Prasad SBV, et al. Efficiency of ultrasound guided aspiration cytology in deep seated lesionsA diagnostic evaluation. Int J Med Health Sci 2012;1(1):2-12

9. Ray S, Gangopadhyay M, Bandyopadhayay A, Majumdar $\mathrm{K}$, Chaudhary N. Ultrasound guided FNAC of ovarian mass lesions. A cytohistopathological correlation with emphasis on its role in preoperative management guidelines. J Turk Gen Gynecol Assoc. 2014;15:6-12.

10. Hemalatha A L, Sumana S, Sushma S. Ultrasound guided FNAC of abdomino-pelvic masses - The patholog ist's perspective. J Clin Diag Res. 2013;7:273-27

11. Sidhalingreddy, Sainath K Andola: Fine needle aspiration cytology of intrabdominal lesion. Journal of clinical and diagnostic research 2011;.5(4):758-65.

*Corresponding author:

Dr. AshimaN.Amin, 503Abhimanheights,haripadav,konchadypost, Kamataka, India pin:575008

Phone: +91 9481955031

Email: dr_ashim13@yahoo.com

Financial or other Competing Interests: None. 